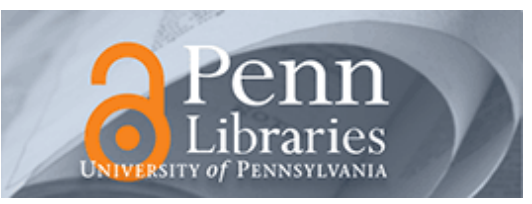

University of Pennsylvania

ScholarlyCommons

$11-2016$

\title{
Clinical and Socio-Demographic Determinants of Self-Care Behaviours in Patients with Heart Failure and Diabetes Mellitus: A Multicentre Cross-Sectional Study
}

Davide Ausili

Paola Rebora

Stefania Di Mauro

Barbara Riegel

University of Pennsylvania, briegel@nursing.upenn.edu

Maria G. Valsecchi

See next page for additional authors

Follow this and additional works at: https://repository.upenn.edu/nrs

Part of the Behavioral Medicine Commons, Cardiology Commons, Cardiovascular Diseases

Commons, Circulatory and Respiratory Physiology Commons, Endocrinology, Diabetes, and Metabolism

Commons, Medical Humanities Commons, Nursing Commons, and the Preventive Medicine Commons

\section{Recommended Citation}

Ausili, D., Rebora, P., Di Mauro, S., Riegel, B., Valsecchi, M. G., Paturzo, M., Alvaro, R., \& Vellone, E. (2016). Clinical and Socio-Demographic Determinants of Self-Care Behaviours in Patients with Heart Failure and Diabetes Mellitus: A Multicentre Cross-Sectional Study. International Journal of Nursing Studies, 63 18-27. http://dx.doi.org/10.1016/j.ijnurstu.2016.08.006

This paper is posted at ScholarlyCommons. https://repository.upenn.edu/nrs/174

For more information, please contact repository@pobox.upenn.edu. 


\title{
Clinical and Socio-Demographic Determinants of Self-Care Behaviours in Patients with Heart Failure and Diabetes Mellitus: A Multicentre Cross-Sectional Study
}

\begin{abstract}
Background

Self-care is vital for patients with heart failure to maintain health and quality of life, and it is even more vital for those who are also affected by diabetes mellitus, since they are at higher risk of worse outcomes. The literature is unclear on the influence of diabetes on heart failure self-care as well as on the influence of socio-demographic and clinical factors on self-care.

Objectives

(1) To compare self-care maintenance, self-care management and self-care confidence of patients with heart failure and diabetes versus those heart failure patients without diabetes; (2) to estimate if the presence of diabetes influences self-care maintenance, self-care management and self-care confidence of heart failure patients; (3) to identify socio-demographic and clinical determinants of self-care maintenance, self-care management and self-care confidence in patients with heart failure and diabetes.
\end{abstract}

Design

Secondary analysis of data from a multicentre cross-sectional study.

Setting

Outpatient clinics from 29 Italian provinces.

Participants

1192 adults with confirmed diagnosis of heart failure.

Methods

Socio-demographic and clinical data were abstracted from patients' medical records. Self-care maintenance, self-care management and self-care confidence were measured with the Self-Care of Heart Failure Index Version 6.2; each scale has a standardized score from 0 to 100, where a score $<70$ indicates inadequate self-care. Multiple linear regression analyses were>performed.

Results

Of 1192 heart failure patients, $379(31.8 \%)$ had diabetes. In these 379 , heart failure self-care behaviours were suboptimal (means range from 53.2 to 55.6). No statistically significant differences were found in any of the three self-care measures in heart failure patients with and without diabetes. The presence of diabetes did not influence self-care maintenance $(p=0.12)$, self-care management $(p=0.21)$ or self-care confidence $(p=0.51)$. Age $(p=0.04)$, number of medications $(p=0.01)$, presence of a caregiver $(p=$ $0.04)$, family income $(p=0.009)$ and self-care confidence $(p<0.001)$ were determinants of self-care maintenance. Gender $(p=0.01)$, number of medications $(p=0.004)$ and self-care confidence $(p<0.001)$ were significant determinants of self-care management. Number of medications $(p=0.002)$ and cognitive function $(p<0.001)$ were determinants of self-care confidence.

Conclusions

Self-care was poor in heart failure patients with diabetes mellitus. This population needs more intensive 
interventions to improve self-care. Determinants of self-care in heart failure patients with diabetes mellitus should be systematically assessed by clinicians to identify patients at risk of inadequate selfcare.

\section{Keywords}

clinical determinants, diabetes mellitus, heart failure, self-care, self-efficacy, social determinants

\section{Disciplines}

Behavioral Medicine | Cardiology | Cardiovascular Diseases | Circulatory and Respiratory Physiology | Endocrinology, Diabetes, and Metabolism | Medical Humanities | Medicine and Health Sciences | Nursing | Preventive Medicine

\section{Author(s)}

Davide Ausili, Paola Rebora, Stefania Di Mauro, Barbara Riegel, Maria G. Valsecchi, Marco Paturzo, Rosaria Alvaro, and Ercole Vellone 


\section{Title}

Clinical and socio-demographic determinants of self-care behaviours in patients with heart failure and diabetes mellitus: a multicentre cross-sectional study

\section{Authors}

1) Davide Ausili, RN, MSc, PhD. Research Fellow in Nursing Science, Department of Medicine and Surgery, University of Milan-Bicocca, Monza, Italy.

2) Paola Rebora, PhD. Assistant Professor in Medical Statistics, Center of Biostatistics for Clinical Epidemiology, Department of Medicine and Surgery, University of Milan-Bicocca, Monza, Italy.

3) Stefania Di Mauro, RN, MSc. Associate Professor in Nursing Science, Department of Medicine and Surgery, University of Milan-Bicocca, Monza, Italy.

4) Barbara Riegel, RN, FAHA, FAAN, PhD. Professor of Nursing, Biobehavioral Research Center, University of Pennsylvania, Philadelphia, Pennsylvania, United States of America.

5) Maria Grazia Valsecchi, PhD. Professor of Medical Statistics, Center of Biostatistics for Clinical Epidemiology, Department of Medicine and Surgery, University of Milan-Bicocca, Monza, Italy.

6) Marco Paturzo, RN, MSc. PhD Candidate, Department of Biomedicine and Prevention, University of Rome Tor Vergata, Rome, Italy.

7) Rosaria Alvaro, RN, MSc. Associate Professor in Nursing Science, Department of Biomedicine and Prevention, University of Rome Tor Vergata, Rome, Italy.

8) Ercole Vellone, RN, MSc, PhD. Research Fellow in Nursing Science, Department of Biomedicine and Prevention, University of Rome Tor Vergata, Rome, Italy.

\section{Corresponding Author}

1) Davide Ausili, RN, MSc, PhD. Research Fellow in Nursing Science, Department of Medicine and Surgery, University of Milan-Bicocca, Monza, Italy.

Address: Via Cadore 48, 20900 Monza, Italy. 
Telephone: +390264488149

Mobile: +393332737039

Email: davide.ausili@unimib.it

\begin{abstract}
Background. Self-care is vital for patients with heart failure to maintain health and quality of life, and it is even more vital for those who are also affected by diabetes mellitus, since they are at higher risk of worse outcomes. The literature is unclear on the influence of diabetes on heart failure self-care as well as on the influence of socio-demographic and clinical factors on self-care.
\end{abstract} Objectives. 1) To compare self-care maintenance, self-care management and self-care confidence of patients with heart failure and diabetes versus those heart failure patients without diabetes; 2) to estimate if the presence of diabetes influences self-care maintenance, self-care management and self-care confidence of heart failure patients; 3) to identify socio-demographic and clinical determinants of self-care maintenance, self-care management and self-care confidence in patients with heart failure and diabetes. Design. Secondary analysis of data from a multicentre crosssectional study. Setting. Outpatient clinics from 29 Italian provinces. Participants. 1,192 adults with confirmed diagnosis of heart failure. Methods. Socio-demographic and clinical data were abstracted from patients' medical records. Self-care maintenance, self-care management and selfcare confidence were measured with the Self-Care of Heart Failure Index Version 6.2; each scale has a standardized score from 0 to 100 , where a score $<70$ indicates inadequate self-care. Multiple linear regression analyses were performed. Results. Of 1,192 heart failure patients, $379(31.8 \%)$ had diabetes. In these 379 , heart failure self-care behaviours were suboptimal (means range from 53.2 to 55.6). No statistically significant differences were found in any of the three self-care measures in heart failure patients with and without diabetes. The presence of diabetes did not influence self-care maintenance $(p=0.12)$, self-care management $(p=0.21)$ or self-care confidence $(p=0.51)$. Age $(\mathrm{p}=0.04)$, number of medications $(\mathrm{p}=0.01)$, presence of a caregiver $(\mathrm{p}=0.04)$, family income $(\mathrm{p}=0.009)$ and self-care confidence $(\mathrm{p}<.001)$ were determinants of self-care maintenance. Gender $(\mathrm{p}=0.01)$, number of medications $(\mathrm{p}=0.004)$ and self-care confidence $(\mathrm{p}$ $<.001)$ were significant determinants of self-care management. Number of medications $(\mathrm{p}=0.002)$ and cognitive function $(\mathrm{p}<.001)$ were determinants of self-care confidence. Conclusions. Self-care was poor in heart failure patients with diabetes mellitus. This population needs more intensive interventions to improve self-care. Determinants of self-care in heart failure patients with diabetes 
mellitus should be systematically assessed by clinicians to identify patients at risk of inadequate self-care.

\section{CONTRIBUTION OF THE PAPER}

\section{What is already known?}

- Self-care is fundamental for patients with heart failure and patients with diabetes mellitus to improve health outcomes and quality of life.

- Patients with heart failure and concomitant diabetes mellitus are at higher risk of adverse events.

\section{What this paper adds?}

- The presence of diabetes mellitus itself does not influence self-care of heart failure patients and no differences in self-care exist between those heart failure patients with and without diabetes mellitus.

- Self-care maintenance, self-care management and self-care confidence are poor in heart failure patients with diabetes but not poorer than that of heart failure patients without diabetes.

- Patients with heart failure and diabetes who are taking more medications are at risk of poor selfcare management but they reported better self-care maintenance and self-care confidence.

\section{What implications for practice and research?}

- Heart failure patients with and without diabetes need more intensive interventions to improve heart failure-related self-care.

- Age, gender, the presence of a caregiver, family income, cognitive function and number of medications should be considered by clinicians to identify heart failure patients with diabetes at higher risk of poor self-care.

- Further studies are needed: to describe diabetes-related self-care in patients with heart failure and diabetes mellitus; to assess if the presence of heart failure could affect diabetes-related self-care in patients with heart failure and diabetes mellitus; and to estimate the effect of diabetes-related selfcare on health outcomes of patients with heart failure and diabetes mellitus. 


\section{INTRODUCTION}

Heart failure is a pandemic syndrome that affects approximately the $1-2 \%$ of the general adult population worldwide (McMurray et al., 2012, Yancy et al., 2013). Heart failure generally affects older adults who suffer from multiple co-morbid and chronic conditions (Dickson et al., 2011, Go et al., 2014, Mozaffarian et al., 2015, Salive, 2013). Diabetes mellitus is one of the most common co-morbid conditions; between $30 \%$ and $47 \%$ of heart failure patients also have diabetes mellitus (Cha et al., 2012, Dunbar et al., 2014, Dungan et al., 2013, Handelsman et al., 2015, Jowsey et al., 2014, Rosland et al., 2010). Diabetes mellitus represents an important risk factor both to the development of heart failure and in triggering worse heart failure outcomes (Dungan et al., 2013, McMurray et al., 2012, Schmitt et al., 2014, Williams et al., 2014, Yancy et al., 2013). In fact, heart failure patients with diabetes mellitus have a $40 \%$ to $80 \%$ increased risk of mortality and a 1.6-fold increased relative risk of hospitalisation compared to those without diabetes mellitus (Dunbar et al., 2014). These issues negatively impact quality of life and healthcare costs. Because heart failure and diabetes mellitus are increasing in prevalence, more and more patients in the future will be affected by concomitant heart failure and diabetes mellitus (Dunbar et al., 2014, Go et al., 2014, Jowsey et al., 2014, Piette et al., 2013, Steventon et al., 2013).

Self-care is considered a cornerstone of heart failure and diabetes mellitus treatment (Dickson et al., 2011, Dunbar et al., 2014, Pare et al., 2010). Self-care was defined as "a process of maintaining health through health promoting practices and managing illness" (Riegel et al., 2012) (p. 195) and includes three dimensions: self-care maintenance, self-care monitoring, and self-care management. Self-care maintenance is the process of maintaining emotional and physical stability when ill. Self-care monitoring is the process of vigilance over signs and symptoms of illness exacerbation. Self-care management is the process of intervening when illness exacerbation is detected (Riegel et al., 2012). Each dimension of self-care is influenced by self-care confidence 
defined as "the ability to perform a specific action and to persist in performing that action despite barriers" (Riegel et al., 2012)(p. 201). In heart failure, self-care reduces hospitalization rates (Kato et al., 2013), health-care costs (Hamar et al., 2015) and mortality (Smith et al., 2014), and improves quality of life (Clark et al., 2015). In diabetes mellitus, self-care improves metabolic control (Walker et al., 2014, Yuan et al., 2014) and quality of life (Chao et al., 2015, Kargar Jahromi et al., 2015) and reduces cardiovascular risk (Powers et al., 2015, Sicuro et al., 2014), hospitalizations (Adepoju et al., 2014) and disease-related complications (Kargar Jahromi et al., 2015, Shreck et al., 2014, Williams et al., 2014). Unfortunately, self-care is suboptimal in both heart failure and diabetes mellitus patients (Cha et al., 2012, Dunbar et al., 2014, Dungan et al., 2013, Jaarsma et al., 2013, Kato et al., 2013, Kerr et al., 2007, Riegel et al., 2009, Saleh et al., 2014, Ware et al., 2006), and when more than one illness is active, self-care becomes particularly challenging (Gallacher et al., 2011, Schmitt et al., 2014). In fact, in heart failure patients, it has been shown that having comorbid conditions impairs self-care confidence (Buck et al., 2015). When self-care confidence is impaired, self-care is lower (Riegel et al., 2011, Vellone et al., 2015). The same process has been shown in diabetes mellitus patients (Grinslade et al., 2015, Walker et al., 2014, Wardian and Sun, 2014, Wardian and Sun, 2015).

To our knowledge, no studies have been conducted comparing self-care maintenance, management and confidence in patients with heart failure and diabetes mellitus to those with only heart failure. It was assumed that the presence of diabetes mellitus could make heart failure selfcare more difficult (Cha et al., 2012, Dunbar et al., 2014). However, it has never been empirically demonstrated that the presence of diabetes mellitus influences heart failure self-care. Prior studies conducted in heart failure patients (Clark et al., 2014, Cocchieri et al., 2015, Oosterom-Calo et al., 2012) have shown that sociodemographic (e.g., male gender) and clinical variables (e.g., shorter illness duration) may be determinants of poor self-care but these determinants have not been described in heart failure patients with diabetes mellitus. Knowing the determinants of self-care may be useful to tailor interventions in this specific population. Therefore, the aims of this study 
were to: 1) compare self-care maintenance, self-care management and self-care confidence in heart failure patients with diabetes mellitus versus those without diabetes mellitus; 2) estimate if the presence of diabetes mellitus in patients with heart failure influences self-care maintenance, selfcare management or self-care confidence of heart failure patients; and 3) identify sociodemographic (age, gender, education, marital status, family income, employment, caregiver support) and clinical (presence of diabetes complications, comorbidity, number of medications taken by patients, cognitive status, duration of illness, New York Heart functional class) determinants of self-care maintenance, self-care management and self-care confidence in patients with heart failure and diabetes.

\section{METHODS}

\section{Design}

A secondary analysis was conducted using data from a multicentre cross-sectional observational study. The aim of the parent study was to describe heart failure patients' self-care and caregiver contributions to patient self-care in the Italian population (Cocchieri et al., 2015, Vellone et al., 2015). The Institutional Review Board of each centre where patients were recruited approved the study. All participants provided informed consent.

\section{Sample and setting}

In the parent study (Cocchieri et al., 2015, Vellone et al., 2015) a convenience sample of 1,192 adults with heart failure was enrolled across 29 Italian provinces. Criteria for patient selections were: patient age $\geq 18$ years and diagnosis of heart failure confirmed by echocardiogram and clinical evidence according to international guidelines (McMurray et al., 2012). Patients were excluded if they had experienced an acute coronary event in the preceding three months or if they had frank dementia.

In this paper, the whole sample of 1,192 patients was used to study if the presence of diabetes mellitus was associated to self-care maintenance, self-care management and self-care 
confidence of heart failure population. To the same aim, a sensitivity analysis, an adjunctive analysis done to check the robustness of previous results (Ding and VanderWeele, 2016), was conducted to assess for possible distortions due to other co-morbid conditions. Sensitivity analysis was performed on a subsample of 459 patients who had only heart failure $(n=339)$ or only heart failure and diabetes $(n=120)$. In other words, in this sensitivity analysis we excluded all patients who had a disease other than heart failure and diabetes. Finally, a subsample of 379 patients with heart failure and diabetes mellitus (including those with other comorbid conditions) was extracted from the whole sample of 1,192 to identify sociodemographic and clinical determinants of self-care maintenance, self-care management and self-care confidence in patients with both the diseases. Detailed information on the analyses performed are provided below.

\section{Data collection and Instruments}

Participants were recruited during outpatient visits. For the purpose of this study the following instruments were used in analysis.

The Self-Care of Heart Failure Index Version 6.2 (Barbaranelli et al., 2014, Riegel et al., 2009) is an instrument used worldwide to measure heart failure self-care. The Self-Care of Heart Failure Index is composed by three scales that measure self-care maintenance, self-care management and self-care confidence. The self-care maintenance scale (10 items) measures how often patients monitor their weight and check their ankles for swelling and how often they adhere to behaviours recommended in clinical guidelines such as taking medications regularly or exercising. The self-care management scale (6 items) measures the ability of patients to evaluate signs and symptoms of a heart failure exacerbation, to implement remedies in response to signs and symptoms and then, to evaluate the effectiveness of those remedies in controlling an illness exacerbation. The self-care confidence scale (6 items) measures task-specific confidence about the ability to manage the processes of self-care. The Self-Care of Heart Failure Index has been demonstrated to be valid and reliable in the American (Barbaranelli et al., 2014, Riegel et al., 2009) and Italian (Vellone et al., 2013) populations. In the Italian context, construct validity of the 
individual scales, tested with confirmatory factor analysis showed the following supportive fit indices: comparative fit index $=.92$ (values $>.90$ are considered acceptable model fit) and root mean square error of approximation $=.05$ (values $\leq .06$ indicate acceptable model fit) for the selfcare maintenance scale; comparative fit index $=.95$, root mean square error of approximation $=.07$ for the self-care management scale; comparative fit index $=.99$, root mean square error of approximation $=.02$ for the self-care confidence scale. Internal consistency (all coefficients $>0.70$ ) and test-retest reliability (all intra-class correlation coefficients $>0.80$ ) were supported as well (Barbaranelli et al., 2014, Vellone et al., 2013). Each Self-Care of Heart Failure Index item uses a Likert type format for responses and a total standardized $0-100$ score is obtained from each of the three scales (self-care maintenance, self-care management and self-care confidence). Higher scores indicate better self-care. A score $\geq 70$ is considered adequate self-care (Riegel et al., 2009).

Patients' socio-demographic data including age, gender, education, marital status, family income, employment status and caregiver support were collected with a questionnaire developed by the research team. Clinical data such as medications taken by the patient, heart failure duration, body mass index, New York Heart Association functional class, ejection fraction, alcohol consumption, and smoking habits were collected by medical record review. Comorbid conditions were measured using the Charlson Comorbidity Index (Charlson et al., 1987). The Charlson Comorbidity Index is a widely used instrument that evaluates the presence of 19 common diseases. Higher Charlson Comorbidity Index scores indicate higher comorbidity. Its predictive validity in the Italian population is supported by previous results (Di Bari et al., 2006, Monami et al., 2007). The Mini Mental State Examination was used to assess cognitive abilities (Folstein et al., 1975). Mini Mental State Examination has been shown to be valid and reliable in the Italian context (Cossa et al., 1997, Cossa et al., 1999). Mini Mental State Examination scores range from 0 to 30 with higher scores indicating better cognition.

\section{Data analysis}


Data analysis was conducted in five steps according to study aims. First, medians, interquartile ranges, means, standard deviations and frequencies, were used to describe sociodemographic and clinical characteristics of heart failure patients with diabetes versus those without diabetes. Second, a comparison of sociodemographic and clinical characteristics of heart failure patients with diabetes mellitus versus heart failure patients without diabetes mellitus was performed. In this comparison, we used the Chi-square test or the Fisher exact test for categorical data, and the Wilcoxon rank-sum test for continuous data.

Third, we compared self-care maintenance, self-care management and self-care confidence scores between heart failure patients with diabetes versus those without diabetes. This comparison was performed adjusting for sociodemographic and clinical variables known to influence self-care maintenance, management and confidence (Bidwell et al., 2015, Clark et al., 2014, Cocchieri et al., 2015, Tsai et al., 2015) and those variables that were significantly different between heart failure patients with diabetes and heart failure patients without diabetes. The variables that were used to adjust the above comparison were: age, gender, Charlson Comorbidity Index score, number of medications, employment status, Mini Mental State Examination score, caregiver presence, education, months of illness, New York Heart Association functional class, number of hospitalizations in the last year, and alcohol consumption.

Fourth, in order to know if the presence of diabetes influenced self-care maintenance, selfcare management and self-care confidence, three multiple linear regression analyses were performed on the whole sample of 1,192 patients. In these regression models self-care maintenance, management and confidence scores were regressed on the following variables: age, gender, Charlson Comorbidity Index score, number of medications, employment status, Mini Mental State Examination score, caregiver presence, education, months of illness, New York Heart Association functional class, number of hospitalizations in the last year, alcohol consumption and the presence of diabetes. In the regression on self-care maintenance and self-care management, another variable added to the model was self-care confidence, since theoretically self-care confidence influences 
both self-care maintenance and self-care management (Riegel and Dickson, 2008, Riegel et al., 2015). Also, in this step, in order to exclude possible distortions of the influence of other comorbid conditions besides diabetes on self-care maintenance, management and confidence, a sensitivity analysis was conducted. In this sensitivity analysis the same multiple linear regression analyses were performed in a subsample of 459 patients with only heart failure or only heart failure and diabetes. In this sensitivity analysis we excluded the Charlson Comorbidity Index score from the regression models since patients of this analysis had no other condition except for heart failure or diabetes.

Fifth, in order to identify sociodemographic and clinical determinants of self-care maintenance, self-care management and self-care confidence in patients with heart failure and diabetes mellitus (aim 3) three multiple linear regression analyses were performed. The following variables were included in each model: age, gender, diabetes complications, Charlson Comorbidity Index score, number of medications taken by patients, employment status, Mini Mental State Examination score, presence of a caregiver, family income, and duration of illness. In the regression analyses on self-care maintenance and self-care management, the self-care confidence score were also included as determinant since, as specified above, self-care confidence influences self-care maintenance and management (Siabani et al., 2016, Vellone et al., 2015). Parameter estimates in these models were combined, according to Rubin (Rubin, 1987), after multiple imputation using a Markov chain Monte Carlo method, performed to account for missing data in the number of medications and other variables (maximum 4\%). Medications were not collected in all centers so 533 patients $(44.7 \%)$ had missing data on this variable. Thus, we assumed that data were missing at random, since clearly the missing data were not related to the outcome itself. For imputation we assumed multivariate normality and considered sociodemographic and clinical characteristics of patients besides self-care maintenance, management and confidence (20 imputed data sets, MI SAS procedure, SAS version 9.4). Sensitivity analyses were performed adopting different imputation methods and similar results were found. 


\section{RESULTS}

Sociodemographic and clinical characteristics of the entire sample (1,192 patients) have been previously published (Cocchieri et al., 2015). In brief, the overall sample had a mean age of 72 years $($ standard deviation $=11)$ and $58 \%$ of them were male. The New York Heart Association functional class was III or IV for those with systolic dysfunction (40\% of the sample, mean ejection fraction $44.6 \%$, standard deviation $=10.9$ ). Among the 1,192 patient included in the parent study, $379(31.8 \%)$ were affected by diabetes mellitus. Table 1 shows sociodemographic characteristics of heart failure patients with and without diabetes mellitus. The two subgroups were similar in gender, marital status, family income, and caregiver presence, but patients with diabetes were significantly older, less well educated, and more likely to be unemployed or retired than patients without diabetes.

Clinically, patients with diabetes mellitus were similar to those without diabetes in body mass index, ejection fraction, and most comorbidities. However, heart failure patients with diabetes had more sleep apnea $(p=0.003)$, anemia $(p=0.023)$, COPD $(p<.001)$, renal disease $(p<.001)$ and prior myocardial infarction $(p=0.014)$ than those without diabetes. Furthermore, the patients with heart failure and diabetes had heart failure for a longer period of time, had a higher co-morbidity severity score, took more medications, and had worse cognition, poorer New York Heart Association functional class, more frequent hospitalizations compared to those without diabetes (Table 2).

Self-care maintenance, self-care management and self-care confidence scores, on average, were inadequate in both subgroups of patients (means range from 53.2 to 55.6), considering that a cut-off score on the Self-Care of Heart Failure Index $\geq 70$ is considered adequate self-care (Riegel et al., 2009). As shown by Figure 1, none of these self-care scores were statistically different between heart failure patients with versus those without diabetes mellitus (aim 1; self-care maintenance $p=0.23$, adjusted $p=0.13$; self-care management $p=0.98$, adjusted $p=0.21$; self- 
care confidence $p=0.87$, adjusted $p=0.51$ ). Accordingly, no statistically significant associations were found between the presence of diabetes and self-care maintenance (parameter estimate $=1.93$; confidence interval $95 \%=-0.55$ to $4.43 ; p=0.13 ;$ r-square $=0.35$ ), self-care management (parameter estimate $=2.61 ;$ confidence interval $95 \%=-1.54$ to $6.56 ; p=0.21 ;$ r-square $=0.39$ ) or self-care confidence (parameter estimate $=1.24$; confidence interval $95 \%=-1.75$ to $4.24 ; p=0.51$; r-square $=0.20)$ after adjusting for age, gender, Charlson Comorbidity Index score, number of medications, employment status, Mini Mental State Examination score, caregiver presence, education, months of illness, New York Heart Association functional class, number of hospitalizations in the last year, and alcohol consumption (aim 2). In the sensitivity analysis performed selecting patients with only heart failure $(n=339)$ and those with only heart failure and diabetes mellitus $(n=120)$, no statistically significant associations were found between self-care maintenance (parameter estimate $=-0.73$; confidence interval $95 \%=-5.13$ to $3.66 ; p=0.74 ; \mathrm{r}$ square $=0.41)$, self-care management $($ parameter estimate $=-1.11 ;$ confidence interval $95 \%=-9.37$ to $7.14 ; p=0.78 ; \mathrm{r}$-square $=0.39$ ), self-care confidence (parameter estimate $=-1.16$; confidence interval $95 \%=-7.29$ to $4.97 ; p=0.70 ;$ r-square $=0.19)$ and the presence of diabetes (aim 2$)$.

Results of the three multiple regression analysis, performed to identify sociodemographic and clinical determinants of the three self-care scales in heart failure patients with diabetes (aim 3) are reported in Table 3. Age $(p=0.04)$, number of medications $(p=0.01)$, presence of a caregiver $(p=0.04)$, family income $(p=0.009)$ and self-care confidence $(p<.001)$ were significant determinants of self-care maintenance, explaining $34 \%$ of the variance in scores. Particularly, number of medications (parameter estimate $=0.90$ ) and self-care confidence $($ parameter estimate $=$ 0.34) were positively associated with self-care maintenance while age (parameter estimate $=-0.20$ ), presence of a caregiver (parameter estimate $=-3.43$ ) and family income (parameter estimate $=$ 1.69) showed a negative association. Gender $(\mathrm{p}=0.01)$, number of medications $(\mathrm{p}=0.004)$ and self-care confidence $(\mathrm{p}<.001)$ were significant determinants of self-care management, explaining $53 \%$ of the variance in scores. Gender (parameter estimate $=-5.42$ ) and number of medications 
(parameter estimate $=-1.53$ ) were negatively associated to self-care management. Otherwise, selfcare confidence (parameter estimate $=0.71$ ) was positively associated with it. Number of medications $(\mathrm{p}=0.002)$ and Mini Mental State Examination score $(\mathrm{p}<.001)$ were significant determinants of self-care confidence, explaining $20 \%$ of the variance in scores. Specifically, both number of medications (parameter estimate $=1.80$ ) and Mini Mental State Examination score (parameter estimate $=1.26$ ) were positively associated with self-care confidence.

\section{DISCUSSION}

To our knowledge, this is the first study considering self-care maintenance, self-care management and self-care confidence in heart failure patients with diabetes mellitus and identifying determinants of these three self-care dimensions in this population. We identified several significant clinical and sociodemographic determinants of self-care maintenance and self-care management. However, our results showed that self-care confidence had the highest effect in both the models explaining respectively self-care maintenance and self-care management. This result confirms available evidence showing that self-care confidence greatly influences self-care maintenance and self-care management also in this group of heart failure patients with diabetes (Dickson et al., 2013, Riegel et al., 2011, Vellone et al., 2015). This finding further supports the situation specific theory of heart failure self-care (Riegel et al., 2015), and the middle range theory on self-care of chronic illness which specify that self-care confidence influences both self-care maintenance and self-care management (Riegel et al., 2012).

We found that being older, taking fewer medications, having a caregiver, having higher family income and lower self-care confidence are risk factors for poor self-care maintenance in heart failure patients with diabetes. It is not surprising that older age is a risk factor, as previous studies have shown that the aging process imposes limitations in self-care maintenance (Bidwell et al., 2015, Buck et al., 2015, Hajduk et al., 2013). The number of medications as well as the number 
of hospital admissions could make patients think that they are very ill, driving them consequently to perform better self-care maintenance. In fact, it has been shown in other studies that heart failure patients delay engaging in self-care maintenance and self-care management until they feel worse and start to have exacerbations more frequently (Siabani et al., 2016, Tsai et al., 2015). Similar results have been found in studies of treatment adherence, an element of self-care maintenance (Conn et al., 2009, Riegel et al., 2012). The presence of a caregiver was associated to poorer selfcare maintenance in the parent study also (Cocchieri et al., 2015). As argued before, this finding could be explained by the fact that the caregiver is more likely to be present when patients have a severe and disabling exacerbation (Bidwell et al., 2015, Clark et al., 2014, Vellone et al., 2014). Thus, self-care maintenance may be poorer when the caregiver is present because the general condition of the patient was poorer, requiring caregiver intervention. In other words, it seems that caregivers are more present in patients' lives when they need to assist with self-care. Family income was not a predictor of self-care maintenance in the heart failure general population (Cocchieri et al., 2015), but it was a predictor in those with both conditions. This finding could be explained by the significant difference in family income between the two groups. We found that income was lower in heart failure patients with diabetes. However, it is surprising that the direction of this relationship suggests that lower income may accentuate disease-related distress and reduce the ability to access care and to perform complex self-care behaviours (Pandit et al., 2014). We suspect that patients with higher incomes pay less attention to a healthy lifestyle and preventive behaviours perhaps because of a demanding lifestyle or because of feeling like they have the resources to face a health problem if it occurs. This finding should be investigated by further by studying the relationship between family income and self-care maintenance in heart failure patients with diabetes.

Being male, taking more medications and having low self-care confidence were risk factors for inadequate self-care management. Some previous studies conducted on heart failure general population have shown that females may perform better self-care maintenance and self-care management than males (Cocchieri et al., 2015, Vellone et al., 2016). This prior result is supported 
in this group of patients with heart failure and diabetes. However, other studies did not found differences in self-care maintenance and management between male and female patients (Lee et al., 2009). Thus, this issue should be further investigated in heart failure population. The number of medications was not a significant predictor of self-care management in the parent study (Cocchieri et al., 2015), suggesting that this variable might become important only when patients are grappling with both heart failure and diabetes mellitus. Patients with diabetes often need to manage a complex medication plan and to titrate their insulin or oral glucose lowering medications (Nagrebetsky et al., 2013, Silva and Bosco, 2015). The addition of heart failure medicines could make it even more difficult for heart failure patients with diabetes to perform self-care management. It appears that the number of medications becomes important when multiple medications are prescribed and self-care management becomes more complex.

Finally, taking fewer medications and having compromised cognition were determinants of poor self-care confidence in heart failure patients with diabetes. Both of these variables were determinants of self-care confidence in heart failure patients (Cocchieri et al., 2015) (Vellone et al., 2016). On one side, the influence of cognition on self-care confidence is not surprising. Our results confirm prior studies showing that heart failure patients with cognitive impairment have lower selfcare maintenance and self-care management (Cocchieri et al., 2015, Hajduk et al., 2013, Harkness et al., 2014, Vellone et al., 2015). On the other side, although these results support those of previous studies (Dickson et al., 2013, Vellone et al., 2015), it is not immediately clear why patients taking more medications have higher self-care confidence. The most likely explanation is that the number of medications could be a surrogate for experience, making patients feel more confident in their ability to perform self-care and to manage the disease. However, this issue needs further investigation.

The variance explained by the tested models ranged from $20 \%$ to $53 \%$. Although these levels are adequate, results suggest that other variables might explain self-care maintenance, selfcare management and self-care confidence in this population. These results confirm that self-care of 
chronic illness is a complex and multidimensional phenomenon and that many factors should be taken into account for its full comprehension (Riegel et al., 2012). The number of medications taken by patients was positively associated to self-care maintenance and self-care confidence but negatively associated to self-care management. Considering that the number of medications was not a predictor of self-care management in the general heart failure population, this unique finding is relevant in these patients, as discussed above. Except for this specific result, overall the determinants of heart failure-related self-care maintenance, self-care management and self-care confidence were very similar in patients with heart failure and diabetes compared to those in the general heart failure population (Cocchieri et al., 2015, Siabani et al., 2016).

Our results suggests that the presence of diabetes itself does not change the predictors of adequate self-care. In fact, we found no significant influence of having diabetes mellitus on heart failure self-care. This finding, confirmed by the analysis including only patients without other comorbidities, could be interpreted in two ways. Heart failure patients with diabetes perform heart failure-related self-care just as well as those without diabetes despite being more clinically compromised. Or, heart failure patients with diabetes are at higher risk for worse outcomes than heart failure patients without diabetes so they should perform better heart failure-related self-care, but they did not. Both interpretations could be relevant. It is not immediately clear why no differences were found, but previous studies demonstrated that patients with multiple co-morbidities focus on one illness for various reasons. They may pay more attention to the disease perceived as more critical or severe or for the disease they have had for a longer period of time (Dickson et al., 2013, Dickson et al., 2011). For this reason, it is possible that patients with both heart failure and diabetes pay the same attention to heart-failure related self-care. Based on our results, we are not able to state if the presence of heart failure influences diabetes-related self-care maintenance, selfcare management and self-care confidence in patients having both diseases. It is also possible that self-care for heart failure and diabetes overlaps for some behaviours and therefore self-care differs 
little for the two diseases. Further research is needed to understand how patients with both illnesses choose to focus their attentions (Cha et al., 2012, Dunbar et al., 2014).

Patients with heart failure and diabetes were significantly older, more likely to be unemployed or retired, and less educated than heart failure patients without diabetes. This result is not surprising; previous investigators also found that diabetes mellitus is associated with lower educational level and more frequent unemployment (Nicolucci et al., 2013, Peyrot et al., 2013). Heart failure patients with diabetes also had more co-morbid conditions. This finding confirms prior research showing that patients with heart failure and diabetes are more clinically compromised and more likely to be hospitalized than heart failure patients without diabetes (Dunbar et al., 2014). This sociodemographic and clinical profile of heart failure patients with diabetes suggests that self-care is vital for this sub-group of heart failure patients if they are to avoid complications (Cha et al., 2012, Ware et al., 2006).

\section{Limitations}

This study has several limitations. The convenience sample, the cross-sectional nature of the study, and the secondary analysis are limitations. Particularly, as a secondary analysis, many important variables describing diabetes were unavailable for analysis. A description of diabetesrelated self-care behaviours also was missing. Variables affecting self-care such as anxiety and depression, which can be modifiable targets of intervention, were not available to be included. Finally, self-care was self-reported, which might not reflect actual self-care behaviours. Another limitation is that we considered the number of medications as a predictor of self-care management even though self-care management may include taking medications (e.g., diuretics) in order to relieve symptoms. Longitudinal studies are needed to understand if self-care management predicts the number of medications taken or vice-versa. However, in this study an inverse relationship was found between these variables: more medications, less self-care management. A strength of the study is that this is the first study describing self-care maintenance, self-care management and selfcare confidence in patients with heart failure and diabetes mellitus. 


\section{CONCLUSIONS}

Self-care is poor in heart failure patients with diabetes, as in the general heart failure population, and they need more intensive interventions to improve self-care. Elements of the sociodemographic and clinical profile can be used to identify patients at risk of poor self-care. We recommend that clinicians systematically evaluate these risk factors to identify patients at risk. In particular, we recommend an evaluation of self-care confidence, because interventions aimed at improving confidence may be particularly effective in improving self-care.

Further research is needed to describe self-care maintenance, self-care management and selfcare confidence in both heart failure and diabetes in order to answer relevant questions concerning self-care of people with both the diseases. Determinants of diabetes-related self-care maintenance, self-care management and self-care confidence should also be examined as well. Prospective designs are needed to evaluate short- and long-term outcomes associated with self-care in this group of patients. Finally, integrated methods and interventions, focusing both on heart failure and diabetes, should be tested to improve self-care in this unique and growing patient population.

\section{Acknowledgements}

Authors acknowledges the Centre of Excellence for Nursing Scholarship of Rome for supporting this study.

\section{Conflict of interest}

The authors declare that there is no conflict of interest.

\section{Funding}

This work was supported by the Centre of Excellence for Nursing Scholarship, Rome, Italy. Grant Number: 2.12.5.

\section{REFERENCES}


Adepoju, O.E., Bolin, J.N., Phillips, C.D., Zhao, H., Ohsfeldt, R.L., McMaughan, D.K., Helduser, J.W., Forjuoh, S.N., 2014. Effects of diabetes self-management programs on time-tohospitalization among patients with type 2 diabetes: a survival analysis model. Patient Educ Couns 95 (1), 111-117.

Barbaranelli, C., Lee, C.S., Vellone, E., Riegel, B., 2014. Dimensionality and reliability of the selfcare of heart failure index scales: further evidence from confirmatory factor analysis. Research in Nursing and Health 37 (6), 524-537.

Barbaranelli, C., Lee, C.S., Vellone, E., Riegel, B., 2014. Dimensionality and reliability of the selfcare of heart failure index scales: further evidence from confirmatory factor analysis. Res Nurs Health 37 (6), 524-537.

Bidwell, J.T., Vellone, E., Lyons, K.S., D'Agostino, F., Riegel, B., Juarez-Vela, R., Hiatt, S.O., Alvaro, R., Lee, C.S., 2015. Determinants of Heart Failure Self-Care Maintenance and Management in Patients and Caregivers: A Dyadic Analysis. Res Nurs Health 38 (5), 392402.

Buck, H.G., Dickson, V.V., Fida, R., Riegel, B., D'Agostino, F., Alvaro, R., Vellone, E., 2015. Predictors of hospitalization and quality of life in heart failure: A model of comorbidity, self-efficacy and self-care. Int J Nurs Stud.

Cha, E., Clark, P.C., Reilly, C.M., Higgins, M., Lobb, M., Smith, A.L., Dunbar, S.B., 2012. Educational needs for improving self-care in heart failure patients with diabetes. Diabetes Educator 38 (5), 673-684.

Cha, E., Clark, P.C., Reilly, C.M., Higgins, M., Lobb, M., Smith, A.L., Dunbar, S.B., 2012. Educational needs for improving self-care in heart failure patients with diabetes. Diabetes Educ 38 (5), 673-684.

Chao, J., Yang, L., Xu, H., Yu, Q., Jiang, L., Zong, M., 2015. The effect of integrated health management model on the health of older adults with diabetes in a randomized controlled trial. Arch Gerontol Geriatr 60 (1), 82-88.

Charlson, M.E., Pompei, P., Ales, K.L., MacKenzie, C.R., 1987. A new method of classifying prognostic comorbidity in longitudinal studies: development and validation. Journal of Chronic Diseases 40 (5), 373-383.

Clark, A.M., Spaling, M., Harkness, K., Spiers, J., Strachan, P.H., Thompson, D.R., Currie, K., 2014. Determinants of effective heart failure self-care: a systematic review of patients' and caregivers' perceptions. Heart 100 (9), 716-721.

Clark, A.P., McDougall, G., Riegel, B., Joiner-Rogers, G., Innerarity, S., Meraviglia, M., Delville, C., Davila, A., 2015. Health Status and Self-care Outcomes After an Education-Support Intervention for People With Chronic Heart Failure. Journal of Cardiovascular Nursing 30 (4 Suppl 1), S3-S13.

Cocchieri, A., Riegel, B., D'Agostino, F., Rocco, G., Fida, R., Alvaro, R., Vellone, E., 2015. Describing self-care in Italian adults with heart failure and identifying determinants of poor self-care. European Journal of Cardiovascular Nursing 14 (2), 126-136.

Conn, V.S., Hafdahl, A.R., Cooper, P.S., Ruppar, T.M., Mehr, D.R., Russell, C.L., 2009. Interventions to improve medication adherence among older adults: meta-analysis of adherence outcomes among randomized controlled trials. Gerontologist 49 (4), 447-462.

Cossa, F.M., Della Sala, S., Musicco, M., Spinnler, H., Ubezio, M.C., 1997. Comparison of two scoring systems of the Mini-Mental State Examination as a screening test for dementia. J Clin Epidemiol 50 (8), 961-965.

Cossa, F.M., Sala, S.D., Musicco, M., Spinnler, H., Ubezio, M.C., 1999. The milan overall dementia assessment and the mini-mental state examination compared: an epidemiological investigation of dementia. Eur J Neurol 6 (3), 289-294.

Di Bari, M., Virgillo, A., Matteuzzi, D., Inzitari, M., Mazzaglia, G., Pozzi, C., Geppetti, P., Masotti, G., Marchionni, N., Pini, R., 2006. Predictive validity of measures of comorbidity in older 
community dwellers: the Insufficienza Cardiaca negli Anziani Residenti a Dicomano Study. J Am Geriatr Soc 54 (2), 210-216.

Dickson, V.V., Buck, H., Riegel, B., 2013. Multiple comorbid conditions challenge heart failure self-care by decreasing self-efficacy. Nurs Res 62 (1), 2-9.

Dickson, V.V., Buck, H., Riegel, B., 2011. A qualitative meta-analysis of heart failure self-care practices among individuals with multiple comorbid conditions. Journal of Cardiac Failure 17 (5), 413-419.

Dickson, V.V., Buck, H., Riegel, B., 2011. A qualitative meta-analysis of heart failure self-care practices among individuals with multiple comorbid conditions. J Card Fail 17 (5), 413-419.

Ding, P., VanderWeele, T.J., 2016. Sensitivity Analysis Without Assumptions. Epidemiology 27 (3), 368-377.

Dunbar, S.B., Butts, B., Reilly, C.M., Gary, R.A., Higgins, M.K., Ferranti, E.P., Culler, S.D., Butler, J., 2014. A pilot test of an integrated self-care intervention for persons with heart failure and concomitant diabetes. Nurs Outlook 62 (2), 97-111.

Dungan, K., Graessle, K., Sagrilla, C., 2013. The effect of congestive heart failure on sensor accuracy among hospitalized patients with type 2 diabetes. Diabetes Technol Ther 15 (10), 817-824.

Folstein, M.F., Folstein, S.E., McHugh, P.R., 1975. Mini Mental State. A practical method for grading the cognitive state of the patients for the clinicians. Journal of Psychiatric Research 12, 189-198.

Gallacher, K., May, C.R., Montori, V.M., Mair, F.S., 2011. Understanding patients' experiences of treatment burden in chronic heart failure using normalization process theory. Annals of Family Medicine 9 (3), 235-243.

Go, A.S., Mozaffarian, D., Roger, V.L., Benjamin, E.J., Berry, J.D., Blaha, M.J., Dai, S., Ford, E.S., Fox, C.S., Franco, S., Fullerton, H.J., Gillespie, C., Hailpern, S.M., Heit, J.A., Howard, V.J., Huffman, M.D., Judd, S.E., Kissela, B.M., Kittner, S.J., Lackland, D.T., Lichtman, J.H., Lisabeth, L.D., Mackey, R.H., Magid, D.J., Marcus, G.M., Marelli, A., Matchar, D.B., McGuire, D.K., Mohler, E.R., 3rd, Moy, C.S., Mussolino, M.E., Neumar, R.W., Nichol, G., Pandey, D.K., Paynter, N.P., Reeves, M.J., Sorlie, P.D., Stein, J., Towfighi, A., Turan, T.N., Virani, S.S., Wong, N.D., Woo, D., Turner, M.B., American Heart Association Statistics, C., Stroke Statistics, S., 2014. Heart disease and stroke statistics--2014 update: a report from the American Heart Association. Circulation 129 (3), e28-e292.

Grinslade, S., Paper, B., Jing, H., Quinn, L., 2015. Development and psychometric evaluation of the Diabetes Self-Efficacy Scale. J Nurs Meas 23 (1), 40-56.

Hajduk, A.M., Lemon, S.C., McManus, D.D., Lessard, D.M., Gurwitz, J.H., Spencer, F.A., Goldberg, R.J., Saczynski, J.S., 2013. Cognitive impairment and self-care in heart failure. Clin Epidemiol 5, 407-416.

Hamar, G.B., Rula, E.Y., Coberley, C., Pope, J.E., Larkin, S., 2015. Long-term impact of a chronic disease management program on hospital utilization and cost in an Australian population with heart disease or diabetes. BMC Health Services Research 15, 174.

Handelsman, Y., Bloomgarden, Z.T., Grunberger, G., Umpierrez, G., Zimmerman, R.S., Bailey, T.S., Blonde, L., Bray, G.A., Cohen, A.J., Dagogo-Jack, S., Davidson, J.A., Einhorn, D., Ganda, O.P., Garber, A.J., Garvey, W.T., Henry, R.R., Hirsch, I.B., Horton, E.S., Hurley, D.L., Jellinger, P.S., Jovanovic, L., Lebovitz, H.E., LeRoith, D., Levy, P., McGill, J.B., Mechanick, J.I., Mestman, J.H., Moghissi, E.S., Orzeck, E.A., Pessah-Pollack, R., Rosenblit, P.D., Vinik, A.I., Wyne, K., Zangeneh, F., 2015. American Association of Clinical Endocrinologists and American College of Endocrinology - Clinical Practice Guidelines for Developing a Diabetes Mellitus Comprehensive Care Plan - 2015. Endocr Pract 21 Suppl 1, 1-87.

Jaarsma, T., Strömberg, A., Ben Gal, T., Cameron J, Driscoll, A., Duengen, H., Huang, T., Huyen, N., Inkrot, S., Kato, N., Köberich, S., Lupón, J., Moser, D., Pulignano, G., Rabelo, E., 
Suwanno, J., Thompson, D., Vellone, E., Alvaro, R., Yu, D., Riegel, B., 2013. Comparison of self-care behaviours of heart failure patients in 15 countries worldwide. Patient Education and Counseling 92, 114-120.

Jowsey, T., Pearce-Brown, C., Douglas, K.A., Yen, L., 2014. What motivates Australian health service users with chronic illness to engage in self-management behaviour? Health Expect 17 (2), 267-277.

Kargar Jahromi, M., Ramezanli, S., Taheri, L., 2015. Effectiveness of diabetes self-management education on quality of life in diabetic elderly females. Glob J Health Sci 7 (1), 10-15.

Kato, N., Kinugawa, K., Nakayama, E., Tsuji, T., Kumagai, Y., Imamura, T., Maki, H., Shiga, T., Hatano, M., Yao, A., Miura, C., Komuro, I., Nagai, R., 2013. Insufficient self-care is an independent risk factor for adverse clinical outcomes in Japanese patients with heart failure. International Heart Journal 54 (6), 382-389.

Kerr, E.A., Heisler, M., Krein, S.L., Kabeto, M., Langa, K.M., Weir, D., Piette, J.D., 2007. Beyond comorbidity counts: how do comorbidity type and severity influence diabetes patients' treatment priorities and self-management? J Gen Intern Med 22 (12), 1635-1640.

Lee, C.S., Riegel, B., Driscoll, A., Suwanno, J., Moser, D.K., Lennie, T.A., Dickson, V.V., Cameron, J., Worrall-Carter, L., 2009. Gender differences in heart failure self-care: a multinational cross-sectional study. Int J Nurs Stud 46 (11), 1485-1495.

McMurray, J.J., Adamopoulos, S., Anker, S.D., Auricchio, A., Bohm, M., Dickstein, K., Falk, V., Filippatos, G., Fonseca, C., Gomez-Sanchez, M.A., Jaarsma, T., Kober, L., Lip, G.Y., Maggioni, A.P., Parkhomenko, A., Pieske, B.M., Popescu, B.A., Ronnevik, P.K., Rutten, F.H., Schwitter, J., Seferovic, P., Stepinska, J., Trindade, P.T., Voors, A.A., Zannad, F., Zeiher, A., 2012. ESC Guidelines for the diagnosis and treatment of acute and chronic heart failure 2012: The Task Force for the Diagnosis and Treatment of Acute and Chronic Heart Failure 2012 of the European Society of Cardiology. Developed in collaboration with the Heart Failure Association (HFA) of the ESC. Eur Heart J 33 (14), 1787-1847.

McMurray, J.J., Adamopoulos, S., Anker, S.D., Auricchio, A., Bohm, M., Dickstein, K., Falk, V., Filippatos, G., Fonseca, C., Gomez-Sanchez, M.A., Jaarsma, T., Kober, L., Lip, G.Y., Maggioni, A.P., Parkhomenko, A., Pieske, B.M., Popescu, B.A., Ronnevik, P.K., Rutten, F.H., Schwitter, J., Seferovic, P., Stepinska, J., Trindade, P.T., Voors, A.A., Zannad, F., Zeiher, A., Bax, J.J., Baumgartner, H., Ceconi, C., Dean, V., Deaton, C., Fagard, R., FunckBrentano, C., Hasdai, D., Hoes, A., Kirchhof, P., Knuuti, J., Kolh, P., McDonagh, T., Moulin, C., Reiner, Z., Sechtem, U., Sirnes, P.A., Tendera, M., Torbicki, A., Vahanian, A., Windecker, S., Bonet, L.A., Avraamides, P., Ben Lamin, H.A., Brignole, M., Coca, A., Cowburn, P., Dargie, H., Elliott, P., Flachskampf, F.A., Guida, G.F., Hardman, S., Iung, B., Merkely, B., Mueller, C., Nanas, J.N., Nielsen, O.W., Orn, S., Parissis, J.T., Ponikowski, P., 2012. ESC guidelines for the diagnosis and treatment of acute and chronic heart failure 2012: The Task Force for the Diagnosis and Treatment of Acute and Chronic Heart Failure 2012 of the European Society of Cardiology. Developed in collaboration with the Heart Failure Association (HFA) of the ESC. Eur J Heart Fail 14 (8), 803-869.

McMurray, J.J., Adamopoulos, S., Anker, S.D., Auricchio, A., Bohm, M., Dickstein, K., Falk, V., Filippatos, G., Fonseca, C., Gomez-Sanchez, M.A., Jaarsma, T., Kober, L., Lip, G.Y., Maggioni, A.P., Parkhomenko, A., Pieske, B.M., Popescu, B.A., Ronnevik, P.K., Rutten, F.H., Schwitter, J., Seferovic, P., Stepinska, J., Trindade, P.T., Voors, A.A., Zannad, F., Zeiher, A., Task Force for the, D., Treatment of, A., Chronic Heart Failure of the European Society of, C., Bax, J.J., Baumgartner, H., Ceconi, C., Dean, V., Deaton, C., Fagard, R., Funck-Brentano, C., Hasdai, D., Hoes, A., Kirchhof, P., Knuuti, J., Kolh, P., McDonagh, T., Moulin, C., Popescu, B.A., Reiner, Z., Sechtem, U., Sirnes, P.A., Tendera, M., Torbicki, A., Vahanian, A., Windecker, S., McDonagh, T., Sechtem, U., Bonet, L.A., Avraamides, P., Ben Lamin, H.A., Brignole, M., Coca, A., Cowburn, P., Dargie, H., Elliott, P., Flachskampf, F.A., Guida, G.F., Hardman, S., Iung, B., Merkely, B., Mueller, C., Nanas, J.N., Nielsen, 
O.W., Orn, S., Parissis, J.T., Ponikowski, P., Guidelines, E.S.C.C.f.P., 2012. ESC guidelines for the diagnosis and treatment of acute and chronic heart failure 2012: The Task Force for the Diagnosis and Treatment of Acute and Chronic Heart Failure 2012 of the European Society of Cardiology. Developed in collaboration with the Heart Failure Association (HFA) of the ESC. Eur J Heart Fail 14 (8), 803-869.

Monami, M., Lambertucci, L., Lamanna, C., Lotti, E., Marsili, A., Masotti, G., Marchionni, N., Mannucci, E., 2007. Are comorbidity indices useful in predicting all-cause mortality in Type 2 diabetic patients? Comparison between Charlson index and disease count. Aging Clin Exp Res 19 (6), 492-496.

Mozaffarian, D., Benjamin, E.J., Go, A.S., Arnett, D.K., Blaha, M.J., Cushman, M., de Ferranti, S., Despres, J.P., Fullerton, H.J., Howard, V.J., Huffman, M.D., Judd, S.E., Kissela, B.M., Lackland, D.T., Lichtman, J.H., Lisabeth, L.D., Liu, S., Mackey, R.H., Matchar, D.B., McGuire, D.K., Mohler, E.R., 3rd, Moy, C.S., Muntner, P., Mussolino, M.E., Nasir, K., Neumar, R.W., Nichol, G., Palaniappan, L., Pandey, D.K., Reeves, M.J., Rodriguez, C.J., Sorlie, P.D., Stein, J., Towfighi, A., Turan, T.N., Virani, S.S., Willey, J.Z., Woo, D., Yeh, R.W., Turner, M.B., American Heart Association Statistics, C., Stroke Statistics, S., 2015. Heart disease and stroke statistics--2015 update: a report from the American Heart Association. Circulation 131 (4), e29-322.

Nagrebetsky, A., Larsen, M., Craven, A., Turner, J., McRobert, N., Murray, E., Gibson, O., Neil, A., Tarassenko, L., Farmer, A., 2013. Stepwise self-titration of oral glucose-lowering medication using a mobile telephone-based telehealth platform in type 2 diabetes: a feasibility trial in primary care. J Diabetes Sci Technol 7 (1), 123-134.

Nicolucci, A., Kovacs Burns, K., Holt, R.I., Comaschi, M., Hermanns, N., Ishii, H., Kokoszka, A., Pouwer, F., Skovlund, S.E., Stuckey, H., Tarkun, I., Vallis, M., Wens, J., Peyrot, M., 2013. Diabetes Attitudes, Wishes and Needs second study (DAWN2): cross-national benchmarking of diabetes-related psychosocial outcomes for people with diabetes. Diabet Med 30 (7), 767-777.

Oosterom-Calo, R., van Ballegooijen, A.J., Terwee, C.B., te Velde, S.J., Brouwer, I.A., Jaarsma, T., Brug, J., 2012. Determinants of heart failure self-care: a systematic literature review. Heart Fail Rev 17 (3), 367-385.

Pare, G., Moqadem, K., Pineau, G., St-Hilaire, C., 2010. Clinical effects of home telemonitoring in the context of diabetes, asthma, heart failure and hypertension: a systematic review. J Med Internet Res 12 (2), e21.

Peyrot, M., Burns, K.K., Davies, M., Forbes, A., Hermanns, N., Holt, R., Kalra, S., Nicolucci, A., Pouwer, F., Wens, J., Willaing, I., Skovlund, S.E., 2013. Diabetes Attitudes Wishes and Needs 2 (DAWN2): a multinational, multi-stakeholder study of psychosocial issues in diabetes and person-centred diabetes care. Diabetes Res Clin Pract 99 (2), 174-184.

Piette, J.D., Rosland, A.M., Marinec, N.S., Striplin, D., Bernstein, S.J., Silveira, M.J., 2013. Engagement with automated patient monitoring and self-management support calls: experience with a thousand chronically ill patients. Med Care 51 (3), 216-223.

Powers, M.A., Bardsley, J., Cypress, M., Duker, P., Funnell, M.M., Hess Fischl, A., Maryniuk, M.D., Siminerio, L., Vivian, E., 2015. Diabetes Self-management Education and Support in Type 2 Diabetes: A Joint Position Statement of the American Diabetes Association, the American Association of Diabetes Educators, and the Academy of Nutrition and Dietetics. Diabetes Care 38 (7), 1372-1382.

Riegel, B., Dickson, V.V., 2008. A situation-specific theory of heart failure self-care. Journal of Cardiovascular Nursing 23 (3), 190-196.

Riegel, B., Dickson, V.V., Faulkner, K.M., 2015. The Situation-Specific Theory of Heart Failure Self-Care: Revised and Updated. J Cardiovasc Nurs. 
Riegel, B., Driscoll, A., Suwanno, J., Moser, D.K., Lennie, T.A., Chung, M.L., Wu, J.R., Dickson, V.V., Carlson, B., Cameron, J., 2009. Heart failure self-care in developed and developing countries. Journal of Cardiac Failure 15 (6), 508-516.

Riegel, B., Jaarsma, T., Stromberg, A., 2012. A middle-range theory of self-care of chronic illness. ANS: Advances in Nursing Science 35 (3), 194-204.

Riegel, B., Lee, C., Vaughan Dickson, V., Carlson, B., 2009. An update on the Self-Care of Heart Failure Index. Journal of Cardiovascular Nursing 24 (6), 485-497.

Riegel, B., Lee, C.S., Albert, N., Lennie, T., Chung, M., Song, E.K., Bentley, B., Heo, S., WorrallCarter, L., Moser, D.K., 2011. From novice to expert: confidence and activity status determine heart failure self-care performance. Nurs Res 60 (2), 132-138.

Riegel, B., Lee, C.S., Dickson, V.V., Carlson, B., 2009. An update on the self-care of heart failure index. Journal of Cardiovascular Nursing 24 (6), 485-497.

Rosland, A.M., Heisler, M., Choi, H.J., Silveira, M.J., Piette, J.D., 2010. Family influences on selfmanagement among functionally independent adults with diabetes or heart failure: do family members hinder as much as they help? Chronic Illness 6 (1), 22-33.

Rubin, D.B., 1987. Multiple Imputation for Nonresponse in Surveys. New York.

Saleh, F., Mumu, S.J., Ara, F., Hafez, M.A., Ali, L., 2014. Non-adherence to self-care practices \& medication and health related quality of life among patients with type 2 diabetes: a crosssectional study. BMC Public Health 14, 431.

Salive, M.E., 2013. Multimorbidity in Older Adults. Epidemiol Rev.

Schmitt, A., Reimer, A., Kulzer, B., Haak, T., Gahr, A., Hermanns, N., 2014. Assessment of diabetes acceptance can help identify patients with ineffective diabetes self-care and poor diabetes control. Diabet Med 31 (11), 1446-1451.

Shreck, E., Gonzalez, J.S., Cohen, H.W., Walker, E.A., 2014. Risk perception and self-management in urban, diverse adults with type 2 diabetes: the improving diabetes outcomes study. Int $\mathbf{J}$ Behav Med 21 (1), 88-98.

Siabani, S., Driscoll, T., Davidson, P.M., Najafi, F., Jenkins, M.C., Leeder, S.R., 2016. Self-care and Its Predictors in Patients With Chronic Heart Failure in Western Iran. J Cardiovasc Nurs 31 (1), 22-30.

Sicuro, J., Charrier, L., Berchialla, P., Cavallo, F., Merlo, S., Mazzeo, A., Porta, M., Trento, M., 2014. Self-management education by group care reduces cardiovascular risk in patients with type 2 diabetes: analysis of the ROMEO clinical trial. Diabetes Care 37 (9), e192-193.

Silva, D.D., Bosco, A.A., 2015. An educational program for insulin self-adjustment associated with structured self-monitoring of blood glucose significantly improves glycemic control in patients with type 2 diabetes mellitus after 12 weeks: a randomized, controlled pilot study. Diabetol Metab Syndr 7, 2.

Smith, C.E., Piamjariyakul, U., Wick, J.A., Spertus, J.A., Russell, C., Dalton, K.M., Elyachar, A., Vacek, J.L., Reeder, K.M., Nazir, N., Ellerbeck, E.F., 2014. Multidisciplinary group clinic appointments: the Self-Management and Care of Heart Failure (SMAC-HF) trial. Circ Heart Fail 7 (6), 888-894.

Steventon, A., Tunkel, S., Blunt, I., Bardsley, M., 2013. Effect of telephone health coaching (Birmingham OwnHealth) on hospital use and associated costs: cohort study with matched controls. BMJ 347, f4585.

Tsai, P.K., Wang, R.H., Lee, C.S., Tsai, L.M., Chen, H.M., 2015. Determinants of self-care decision-making in hospitalised patients with heart failure. J Clin Nurs 24 (7-8), 1101-1111.

Vellone, E., D'Agostino, F., Buck, H.G., Fida, R., Spatola, C.F., Petruzzo, A., Alvaro, R., Riegel, B., 2015. The key role of caregiver confidence in the caregiver's contribution to self-care in adults with heart failure. Eur J Cardiovasc Nurs 14 (5), 372-381.

Vellone, E., D'Agostino, F., Buck, H.G., Fida, R., Spatola, C.F., Petruzzo, A., Alvaro, R., Riegel, B., 2014. The key role of caregiver confidence in the caregiver's contribution to self-care in adults with heart failure. European Journal of Cardiovascular Nursing. 
Vellone, E., Fida, R., D'Agostino, F., Mottola, A., Juarez-Vela, R., Alvaro, R., Riegel, B., 2015. Self-care confidence may be the key: A cross-sectional study on the association between cognition and self-care behaviors in adults with heart failure. Int J Nurs Stud.

Vellone, E., Fida, R., Ghezzi, V., D'Agostino, F., Biagioli, V., Paturzo, M., Stromberg, A., Alvaro, R., Jaarsma, T., 2016. Patterns of Self-care in Adults With Heart Failure and Their Associations With Sociodemographic and Clinical Characteristics, Quality of Life, and Hospitalizations: A Cluster Analysis. J Cardiovasc Nurs.

Vellone, E., Pancani, L., Greco, A., Steca, P., Riegel, B., 2016. Self-care confidence may be more important than cognition to influence self-care behaviors in adults with heart failure: Testing a mediation model. Int J Nurs Stud 60, 191-199.

Vellone, E., Riegel, B., Cocchieri, A., Barbaranelli, C., D'Agostino, F., Antonetti, G., Glaser, D., Alvaro, R., 2013. Psychometric properties of the self-care of heart failure index version 6.2. Research in Nursing and Health 36 (5), 500-511.

Walker, R.J., Smalls, B.L., Hernandez-Tejada, M.A., Campbell, J.A., Egede, L.E., 2014. Effect of diabetes self-efficacy on glycemic control, medication adherence, self-care behaviors, and quality of life in a predominantly low-income, minority population. Ethn Dis 24 (3), 349355.

Wardian, J., Sun, F., 2014. Factors associated with diabetes-related distress: implications for diabetes self-management. Soc Work Health Care 53 (4), 364-381.

Wardian, J., Sun, F., 2015. Removing barriers to promote more positive thinking for people with diabetes: implications for social work. Soc Work 60 (2), 175-182.

Ware, M.G., Flavell, C.M., Lewis, E.F., Nohria, A., Warner-Stevenson, L., Givertz, M.M., 2006. Heart failure and diabetes: collateral benefit of chronic disease management. Congest Heart Fail 12 (3), 132-136.

Williams, I.C., Utz, S.W., Hinton, I., Yan, G., Jones, R., Reid, K., 2014. Enhancing diabetes selfcare among rural African Americans with diabetes: results of a two-year culturally tailored intervention. Diabetes Educ 40 (2), 231-239.

Yancy, C.W., Jessup, M., Bozkurt, B., Butler, J., Casey, D.E., Jr., Drazner, M.H., Fonarow, G.C., Geraci, S.A., Horwich, T., Januzzi, J.L., Johnson, M.R., Kasper, E.K., Levy, W.C., Masoudi, F.A., McBride, P.E., McMurray, J.J., Mitchell, J.E., Peterson, P.N., Riegel, B., Sam, F., Stevenson, L.W., Tang, W.H., Tsai, E.J., Wilkoff, B.L., American College of Cardiology, F., American Heart Association Task Force on Practice, G., 2013. 2013 ACCF/AHA guideline for the management of heart failure: a report of the American College of Cardiology Foundation/American Heart Association Task Force on Practice Guidelines. Journal of the American College of Cardiology 62 (16), e147-239.

Yuan, C., Lai, C.W., Chan, L.W., Chow, M., Law, H.K., Ying, M., 2014. The effect of diabetes self-management education on body weight, glycemic control, and other metabolic markers in patients with type 2 diabetes mellitus. J Diabetes Res 2014, 789761. 
Table 1. Socio-demographic characteristics of heart failure patients with and without diabetes mellitus.

\begin{tabular}{|c|c|c|c|}
\hline & \multicolumn{2}{|c|}{ Diabetes } & \multirow[t]{3}{*}{$\mathrm{P}$} \\
\hline & $\begin{array}{c}\text { Yes } \\
(n=379)\end{array}$ & $\begin{array}{c}\text { No } \\
(\mathrm{n}=813)\end{array}$ & \\
\hline & $\mathrm{n}(\%)$ & $\mathrm{n}(\%)$ & \\
\hline Patient Gender & & & 0.767 \\
\hline Female & $156(41)$ & $342(42)$ & \\
\hline Male & 223(59) & $471(58)$ & \\
\hline Age (median, interquartile range) & $75(68-80)$ & $73(65-80)$ & 0.010 \\
\hline Education & & & 0.023 \\
\hline Less than high school & $319(84)$ & $628(78)$ & \\
\hline High school & $41(11)$ & $129(16)$ & \\
\hline University degree & $18(5)$ & $53(7)$ & \\
\hline Marital Status & & & 0.052 \\
\hline Single & $23(6)$ & $57(7)$ & \\
\hline Married & $225(59)$ & $452(56)$ & \\
\hline Divorced & $14(4)$ & $63(8)$ & \\
\hline Widowed & $117(31)$ & $241(30)$ & \\
\hline Family Income in Euros & & & 0.147 \\
\hline $0-1000$ & $123(33)$ & $238(30)$ & \\
\hline
\end{tabular}




$\begin{array}{lll}1001-2000 & 192(51) & 410(51) \\ >2000 & 56(15) & 157(20)\end{array}$

Employment status $<0,001$
Unemployed/Retired
334(88)
644(79)
Employed
45(12)
169(21)

Presence of a caregiver
No
91(24)
198(25)
Yes
286(76)
611(76)

Note. $\mathrm{DM}=$ diabetes mellitus; All variables were tested with a chi-square test except age that was tested using a twosided Wilcoxon rank-sum test.

*For the Age variable median and $1^{\text {st }}-3^{\text {rd }}$ interquartile range are presented.

Table 2. Clinical characteristics of heart failure patients with and without diabetes mellitus.

\begin{tabular}{|c|c|c|c|}
\hline & \multicolumn{2}{|c|}{ Diabetes Mellitus } & \multirow[t]{2}{*}{$\mathbf{P}$} \\
\hline & $\begin{array}{c}\text { Yes } \\
(\mathrm{n}=379) \\
\text { median[1st-3rd } \\
\text { quartile] }\end{array}$ & $\begin{array}{c}\text { No } \\
(\mathrm{n}=813) \\
\text { median[1st-3rd } \\
\text { quartile] }\end{array}$ & \\
\hline Body Mass Index & $27[25-29]$ & $27[24-29]$ & 0.208 \\
\hline Year of illness & $4[2-7]$ & $3[2-5]$ & 0.001 \\
\hline Ejection Fraction (percentage) & $45[36-50]$ & $45[38-52]$ & 0.228 \\
\hline Charlson Co-morbidity Index Score & $3[2-4]$ & $2[2-3]$ & $<.001$ \\
\hline Number of medications & $6[4-8]$ & $4[3-6]$ & $<.001$ \\
\hline Mini Mental State Examination score & $\begin{array}{l}24[19-28] \\
\mathrm{n}(\%)\end{array}$ & $\begin{array}{l}26[22-30] \\
\mathrm{n}(\%)\end{array}$ & $<.001$ \\
\hline New York Heart Association Class & & & 0.043 \\
\hline $\mathbf{I}$ & $52(14)$ & $145(18)$ & \\
\hline II & 152(40) & $355(44)$ & \\
\hline III & $138(36)$ & $255(31)$ & \\
\hline IV & $37(10)$ & $56(7)$ & \\
\hline $\begin{array}{l}\text { Number of hospitalization in the last } \\
\text { year }\end{array}$ & & & $<.001$ \\
\hline Never & $133(35)$ & $409(50)$ & \\
\hline Once & 147(39) & $276(34)$ & \\
\hline Twice & $59(16)$ & $100(12)$ & \\
\hline$>2$ times & $40(11)$ & $28(3)$ & \\
\hline
\end{tabular}




\begin{tabular}{lccc}
\hline Atrial Fibrillation & $161(43)$ & $301(37)$ & 0.076 \\
Sleep Apnea & $67(18)$ & $94(12)$ & 0.003 \\
High Blood Pressure & $272(72)$ & $539(66)$ & 0.063 \\
Anemia & $94(27)$ & $158(21)$ & 0.023 \\
Pulmonary Hypertension & $23(6)$ & $54(7)$ & 0.717 \\
Peripheral vascular disease & $66(17)$ & $124(15)$ & 0.332 \\
Stroke & $41(12)$ & $68(9)$ & 0.192 \\
Hemiplegia & $20(5)$ & $38(5)$ & 0.652 \\
Chronic Obstructive Pulmonary Disease & $144(38)$ & $235(29)$ & $<.001$ \\
Peptic Ulcer & $44(12)$ & $78(10)$ & 0.291 \\
Renal disease & $80(21)$ & $91(11)$ & $<.001$ \\
Connective Tissue disease & $11(3)$ & $19(2)$ & 0.563 \\
Mild Liver Disease & $20(5)$ & $40(5)$ & 0.777 \\
Severe Liver Disease & $2(1)$ & $4(1)$ & 0.936 \\
Leukemia & $2(1)$ & $6(1)$ & 1.000 \\
Lymphoma & $1(0)$ & $6(1)$ & 0.441 \\
Cancer without metastasis & $5(1)$ & $21(3)$ & 0.163 \\
Cancer with metastasis & $20(5)$ & $29(4)$ & 0.167 \\
Prior Myocardial Infarction & $149(43)$ & $258(35)$ & 0.014 \\
\hline Note. Body Mass Index, Yer of $i l l n e s s$, Ejection Fraction
\end{tabular}

Note. Body Mass Index, Year of illness, Ejection Fraction, Charlson Comorbidity Index Score, Number of medications,

MMSE score were tested using a two-sided Wilcoxon rank-sum test. NYHA Class, Number of hospitalizations, Atrial Fibrillation, Sleep Apnea, High Blood Pressure, Anemia, Pulmonary Hypertension, Peripheral vascular disease, Stroke, Hemiplegia, COPD, Peptic Ulcer, Renal disease, Connective Tissue disease, Mild Liver Disease, Severe Liver Disease, Cancer without metastasis, Cancer with metastasis, Prior Myocardial Infarction were tested using chi-square test. Leukemia and Lymphoma were tested by an exact Fisher test. 
Figure 1. Comparison of self-care maintenance, self-care management and self-care confidence means and medians between heart failure patients with diabetes mellitus $(n=379)$ and without diabetes mellitus $(n=813)$. 
a) Self-care maintenance

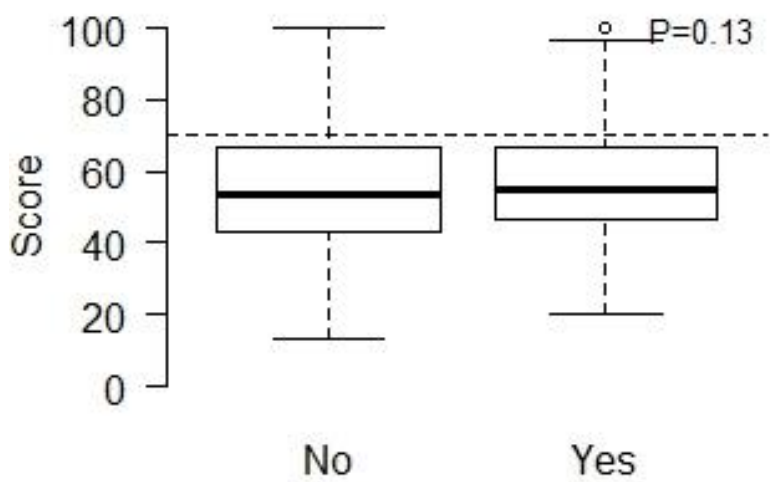

Diabetes

c) Self-care confidence

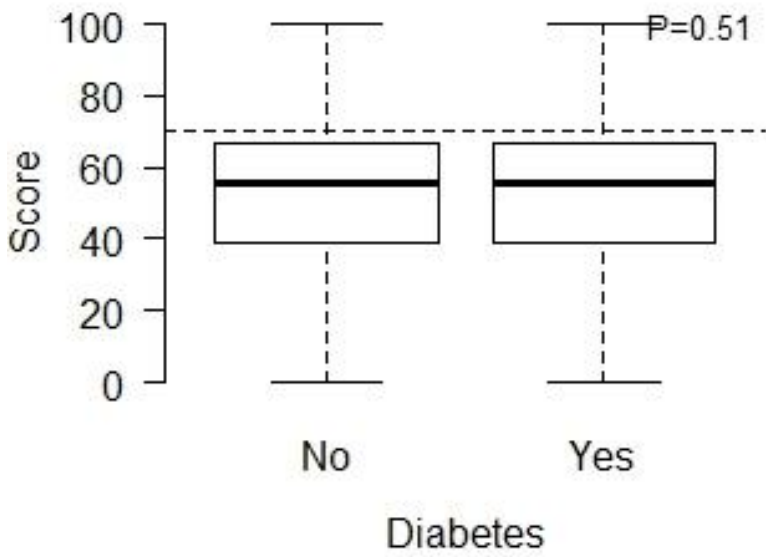

b) Self-care management

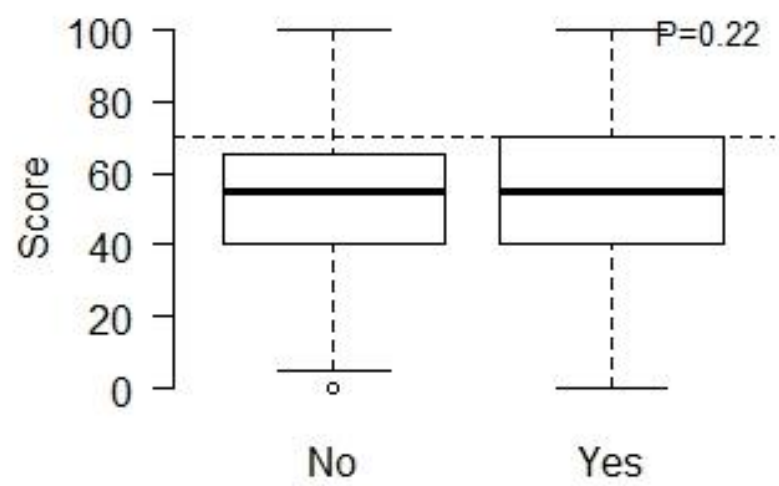

Diabetes

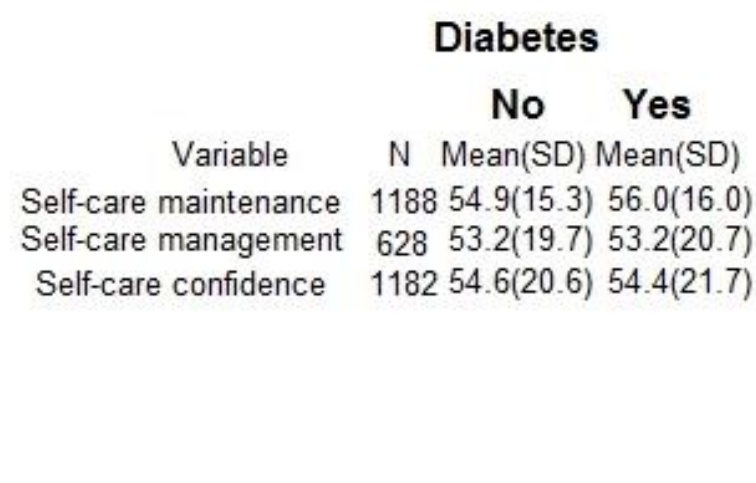

\section{No Yes}

Self-care maintenance $118854.9(15.3) 56.0(16.0)$

Self-care management $628 \quad 53.2(19.7) 53.2(20.7)$

Self-care confidence $118254.6(20.6) 54.4(21.7)$

Note. Sample size in self-care management dimension is lower (628) because this scale was administered only to patients who reported symptoms of heart failure in the last month. P-values derived by multiple linear regression adjusting for age, gender, Charlson Comorbidity Index score, number of medications, employment status, Mini Mental State Examination score, caregiver presence, education, months of illness, New York heart Association functional class, number of hospitalizations in the last year, alcohol consumption and self-care confidence (this last one only in the regression analysis on self-care maintenance and self-care management).

Table 3. Socio-demographic and clinical determinants of self-care maintenance, self-care management and self-care confidence in heart failure patients with diabetes mellitus $(n=379)$. 


\begin{tabular}{|c|c|c|c|}
\hline & & Parameter & \\
\hline Variable & $\mathrm{R}$-square & $\begin{array}{l}\text { Estimate } \\
(95 \% \mathrm{CI})\end{array}$ & $\mathrm{p}$ value \\
\hline Determinants of self-care maintenance $(n=379)$ & 0.34 & & \\
\hline Age & & $\begin{array}{c}-0.20(-0.40-- \\
0.007)\end{array}$ & 0.042 \\
\hline Gender & & $-1.01(-3.83-1.79)$ & 0.471 \\
\hline Presence of diabetes complications & & $-0.28(-2.20-1.63)$ & 0.771 \\
\hline Charlson Comorbidity Index score & & $-0.20(-1.37-0.97)$ & 0.735 \\
\hline Number of medications taken by patients & & $0.90(0.15-1.65)$ & 0.017 \\
\hline Employment status & & $-0.39(-5.60-4.82)$ & 0.883 \\
\hline Mini Mental State Examination score & & $-0.02(-0.29-0.24)$ & 0.847 \\
\hline Presence of a caregiver & & $-3.43(-6.82--0.05)$ & 0.046 \\
\hline Family Income & & $-1.69(-2.96--0.4)$ & 0.009 \\
\hline Month of Illness & & $0.02(0.005-0.53)$ & 0.105 \\
\hline New York Heart Association Class & & $-1.72(-3.62-0.17)$ & 0.074 \\
\hline Self-care confidence & & $0.34(0.26-0.40)$ & $<.001$ \\
\hline Determinants of self-care management $(n=215)$ & 0.53 & & \\
\hline Age & & $0.13(-0.17-0.43)$ & 0.396 \\
\hline Gender & & $-5.42(-9.73--1.12)$ & 0.013 \\
\hline Presence of diabetes complications & & $0.79(-1.92-3.51)$ & 0.568 \\
\hline Charlson Comorbidity Index score & & $-0.55(-2.44-1.33)$ & 0.564 \\
\hline Number of medications taken by patients & & $-1.53(-2.59--0.47)$ & 0.004 \\
\hline Employment status & & $2.30(-6.54-11.16)$ & 0.609 \\
\hline Mini Mental State Examination score & & $-0.26(-0.65-0.11)$ & 0.170 \\
\hline Presence of a caregiver & & $0.60(-4.73-5.93)$ & 0.825 \\
\hline Family Income & & $0.47(-1.47-2.43)$ & 0.630 \\
\hline Months of Illness & & $-0.002(-0.04-0.04)$ & 0.910 \\
\hline New York Heart Association Class & & $-2.15(-4.99-0.69)$ & 0.138 \\
\hline Self-care confidence & & $0.71(0.60-0.82)$ & $<.001$ \\
\hline Determinants of self-care confidence $(n=379)$ & 0.20 & & \\
\hline Age & & $-0.20(-0.50-0.08)$ & 0.165 \\
\hline Gender & & $-1.45(-5.64-2.73)$ & 0.497 \\
\hline Presence of diabetes complications & & $2.72(-0.13-5.58)$ & 0.062 \\
\hline Charlson Comorbidity Index score & & $0.002(-1.76-1.77)$ & 0.997 \\
\hline Number of medications taken by patients & & $1.80(0.66-2.94)$ & 0.002 \\
\hline Employment status & & $-1.18(-8.95-6.57)$ & 0.764 \\
\hline Mini Mental State Examination score & & $1.26(0.88-1.64)$ & $<.001$ \\
\hline Presence of a caregiver & & $-2.71(-7.73-2.31)$ & 0.290 \\
\hline Family Income & & $-0.31(-2.21-1.58)$ & 0.743 \\
\hline Month of Illness & & $0.004(-0.03-0.04)$ & 0.835 \\
\hline New York Heart Association Class & & $-1.13(-3.92-1.66)$ & 0.427 \\
\hline
\end{tabular}

Note. The three models were performed on imputed data. Sample size in the regression of self-care management is lower $(n=215)$ because this scale is administered only to patients who reported symptoms of heart failure in the last month. 